\title{
The Need of Holistic Interventions in Schools: The Promotion of Healthy and Sustainable Personal Development among Children \\ Danilo Garcia ${ }^{1-6^{*}}$, Anders Drugge ${ }^{7}$, Helen Blixt Samuelsson ${ }^{7}$, Ulrika Storm ${ }^{7}$, Trevor Archer ${ }^{2,3}$ and Kevin M Cloninger $^{4}$
}

${ }^{1}$ Blekinge Centre of Competence, Blekinge County Council, Karlskrona, Sweden

${ }^{2}$ Department of Psychology, University of Gothenburg, Gothenburg, Sweden

${ }^{3}$ Network for Empowerment and Well-Being, Sweden

${ }^{4}$ Anthropedia Foundation, Washington, Missouri, USA

${ }^{5}$ Institute of Neuroscience and Physiology, University of Gothenburg, Gothenburg, Sweden

${ }^{6}$ Department of Psychology, Lund University, Lund, Sweden

${ }^{7}$ Department of Psychology, Linnaeus University, Växjö, Sweden

"Intelligence plus character--that is the goal of true education." Martin Luther King Jr.

Children need adults' support and influence to learn to describe and put words to their feelings and to develop empathy $[1,2]$. Interventions and preventions studies show that social cognitive training programs, for example, influence children's level of empathy in a positive direction [3] and that training in "stepping into the shoes of others" for a year improves children's theory of mind [4]. Although not all studies consider gender when assessing the effect of different interventions, gender differences are relatively commonly acceptedgirls express and report higher levels of empathy compared to boys and empathy training has a greater impact on girls as well [3]. Interestingly, some theories suggest that children at certain age are not able to predict how others would react in certain situations [5]. Thus, it is important to design these types of interventions and preventions by taking into account both the age and gender of the child. Additionally, the development of a theory of mind is closely related to the development of character or what people make of themselves intentionally, their values, and goals [6]. It is our opinion that interventions at school should target the development of, besides empathy per se, character development. Here we first present a biopsychosociospiritual model of human personality, secondly, two interventions that are relatively common in Sweden for the development of children's social and emotional skills and then detail a non-published study in which differences in character point to areas of development for interventions at schools.

\section{Cloninger's Biopsychosociospiritual Model of Personality}

Character is one of two domains of personality in Cloninger's biopsychosociospiritual model of personality. Character accounts for emotional regulation, that is, it stands for individuals' sense of autonomy, responsibility, self-control, self-acceptance, helpfulness, cooperation, tolerance towards others, and a sense of belonging and meaningfulness greater than the self [6-8]. This system of self-government is organized around goals and values with regard to the self (i.e., self-directedness), others (i.e., cooperativeness), and something bigger than the self (i.e., self-transcendence). The second domain of personality is temperament, which comprises the system responsible for our likes and dislikes, that is, emotional reactions [6]. Temperament is divided in four dimensions (i.e., novelty seeking, harm avoidance, reward dependence, and persistence) that stand for emotions such as joy, sadness, fear, anger, and disgust. Cloninger's model is a holistic model of personality that takes into account the body (i.e., temperament), the mind (i.e., selfdirectedness and cooperativeness), and the psyche or soul aspect of personality (i.e., self-transcendence; see Figure 1). Importantly, although both personality domains seem to be equally influenced

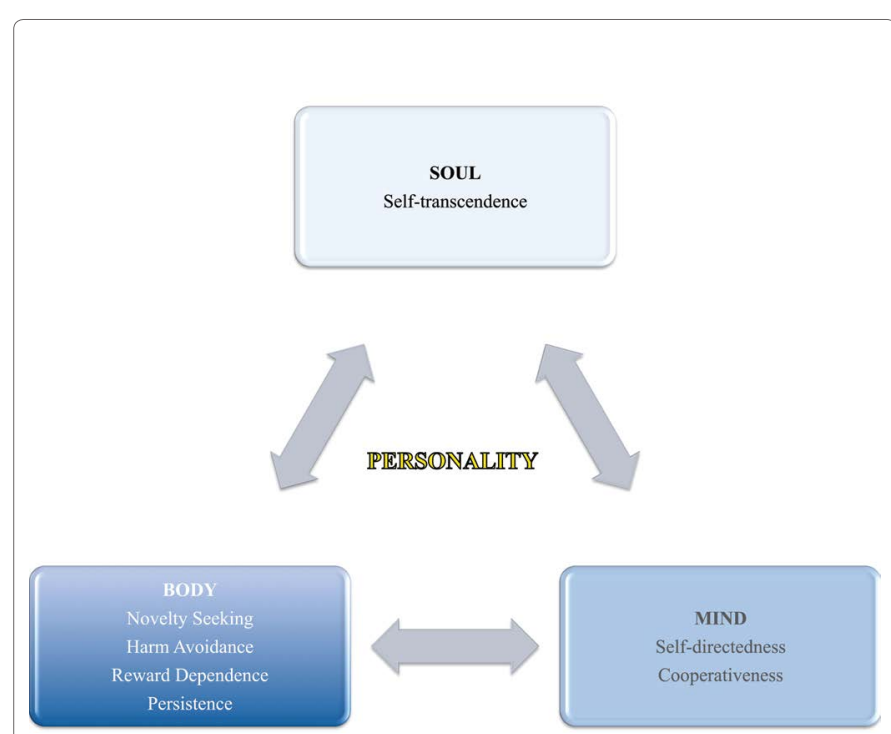

Figure 1: Personality as a holistic view of the human being (i.e., body, mind, and soul). Reprinted with permission from C. R. Cloninger.

by genes (for a review see [9],) character changes over time, while temperament seems to remain relatively stable through the life span [10]. What is more, twin studies show that there is greater consistency, between findings among adolescents and adults samples, in the proportion of additive genetic effect to non-shared environmental effect with respect to temperament but not with respect to character. These results actually suggest a "shift" in type of environmental influence (i.e., shared to non-shared) from adolescence to adulthood with regard to character [11,12]. In other words, interventions targeting character might be more effective during adolescence. Interestingly, many psychiatric problems manifest between 9-12 years of age.

\section{Popular Interventions in Swedish School Settings}

In an explorative non-published pilot study, detailed below,

*Corresponding author: Garcia D, Network for Empowerment and Well-Being Axel W. Anderssons Väg 8A, SE 371 62, Lyckeby, Sweden, Tel: +46 31 7864694; E-mail: danilo.garcia@icloud.com

Received: April 19, 2016; Accepted: May 02, 2016; Published: May 09, 2016

Citation: Garcia D, Drugge A, Samuelsson HB, Storm U, Archer T, et al. (2016) The Need of Holistic Interventions in Schools: The Promotion of Healthy and Sustainable Personal Development among Children. Clin Exp Psychol 2: 129. doi:10.4172/2471-2701.1000129

Copyright: ( 2016 Garcia D, et al. This is an open-access article distributed under the terms of the Creative Commons Attribution License, which permits unrestricted use, distribution, and reproduction in any medium, provided the original author and source are credited. 
researchers investigated differences in personality among children who had participated in two specific types of interventions: Four Rooms of Change and EQ-workshop [13]. The Children's Four Rooms of Change intervention is a method used to develop the children's socio-emotional skills by allowing children to identify, express, and manage their feelings in front of the class. A self-assessment instrument predefines the four "rooms": (1) Contentment, (2) Self-Censorship and Denial, (3) Confusion and Conflict, and (4) Inspiration and Renewal. However, the children are encouraged to label the "rooms" by themselves. Essentially, each child is asked to tell the class in which "room" she/he is in that specific day and moment. In that way, it is expected that children develop their emotional vocabularies in order to facilitate discussions about everyday emotional states. This increased awareness of own emotions and that of their peers is expected to reduce bullying behaviors (see http://www.fourroomsofchange.net.au/ tools-that-work-s.php). The other intervention is the EQ-workshop, which is a method developed around roll playing in which children are, for example, asked to collaborate in order to solve puzzles that involve body contact or to show if they agree or disagree to statements/actions in relevant moral dilemmas (e.g., a kid having a bad day at school) by moving from one place to another. The children are then encouraged to disseminate the way they thought about their decisions or way of solving the tasks (http://www.eqverkstan.se).

\section{Results by Explorative Pilot Study}

In this unpublished study Drugge et al. [13], the three different schools, in the South of Sweden, that were chosen to participate were judged as similar to each other in relation to the socioeconomic status and cultural diversity. In addition, two of the schools conducted either the Four Rooms of Change or the EQ-workshop intervention among their pupils. The third school, the control group, did not conduct any official or explicit intervention for the children's character development. As all schools in Sweden, however, this third school followed the guidelines from the curriculum established by the Swedish National Agency for Education (http://www.skolverket.se/om-skolverket/ andra-sprak-och-lattlast/in-english). The final sample was 29 boys and 26 girls (dropout is $12.70 \%$ ). The biopsychosociospiritual model of personality was operationalized using the Junior Temperament and Character Inventory [14]. The instrument comprises 108 items that are answered using a binary scale ("yes" coded as 1, "no" coded as 0 ). Examples of items for each personality dimension are: "Sometimes even little things make me lose my temper" (novelty seeking), "When I try something new, I feel uncomfortable and nervous" (harm avoidance),
"I usually cry when I see sad movies." (reward dependence), "I try harder than other kids because I want to do my very best" (persistence), "I am the one who is responsible for what I do" (self-directedness), "I like to share what I have learned with other kids" (cooperativeness), and "I sometimes feel like living things are really connected" (selftranscendence).

Boys and girls differed slightly only in one temperament dimension, namely, reward dependence and none of the character dimensions (see Table 1). No differences in personality were found between children from any of the schools. Interestingly, there was an interaction effect for character traits but not for temperament traits. In other words boys and girls from the different schools seemed to have the same or at least not significantly different temperamental dispositions, but they did differ in their ability to regulate their emotions. For example, compared to boys in the Four Rooms of Change, girls receiving this same intervention reported more self-acceptance, more self-control, being more goal-oriented (i.e., high self-directedness) and also being more tolerant, helpful, and empathic (i.e., high cooperativeness)- boys who participated in the EQ-workshop intervention scoring the highest in self-directedness (Figure 2a) and girls in the control group scoring the highest in cooperativeness (Figure $2 \mathrm{~b}$ ). With respect to self-transcendence, boys in the control group scored higher than girls in the same group and girls in the EQ-workshop scored higher than boys receiving the same intervention. Nevertheless, boys in the control group were the ones who reported higher levels of spirituality, awareness, and more frequently experiencing flow compared to all other children in any of the interventions (i.e., self-transcendence; Figure 2c).

It is plausible to expect that children who participate in interventions that aim to develop empathy, collaboration, and self-awareness should show differences in character when compared to those children who are being educated under the common curriculum. Nevertheless, the study reviewed here was only a cross-sectional pilot study and the researchers did not aim to evaluate the interventions per se. The results, however, suggest that the biopsychosociospiritual model of personality developed by Cloninger seems to be useful to point at areas of development. What is more, this model of personality involves a holistic view of the human being and allows the investigation of personality as a non-linear dynamic system. That is, the study of an individual who is adapting to internal and external influences [15-18]. More recently, interventions on well-being coaching have been developed and are being tested in different settings (http://anthropedia.org).

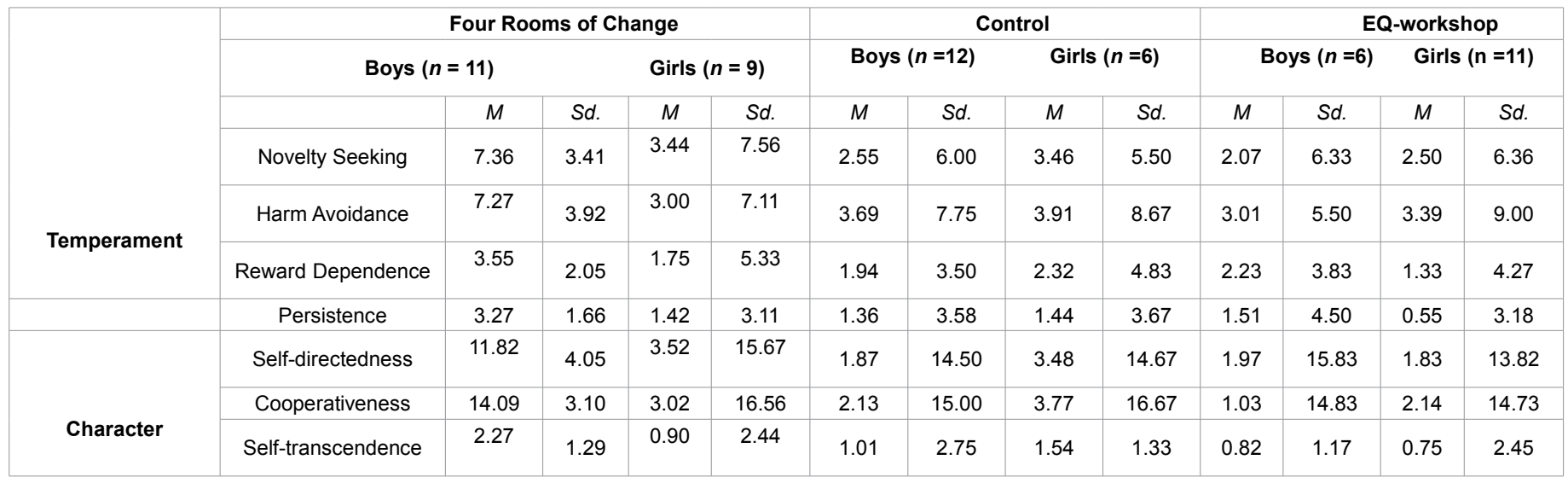

Table 1: Means and standard deviation (sd.) in temperament and character measured by the junior temperament and character inventory for boys and girls in the different interventions and the control group 
Citation: Garcia D, Drugge A, Samuelsson HB, Storm U, Archer T, et al. (2016) The Need of Holistic Interventions in Schools: The Promotion of Healthy and Sustainable Personal Development among Children. Clin Exp Psychol 2: 129. doi:10.4172/2471-2701.1000129

Page 3 of 3
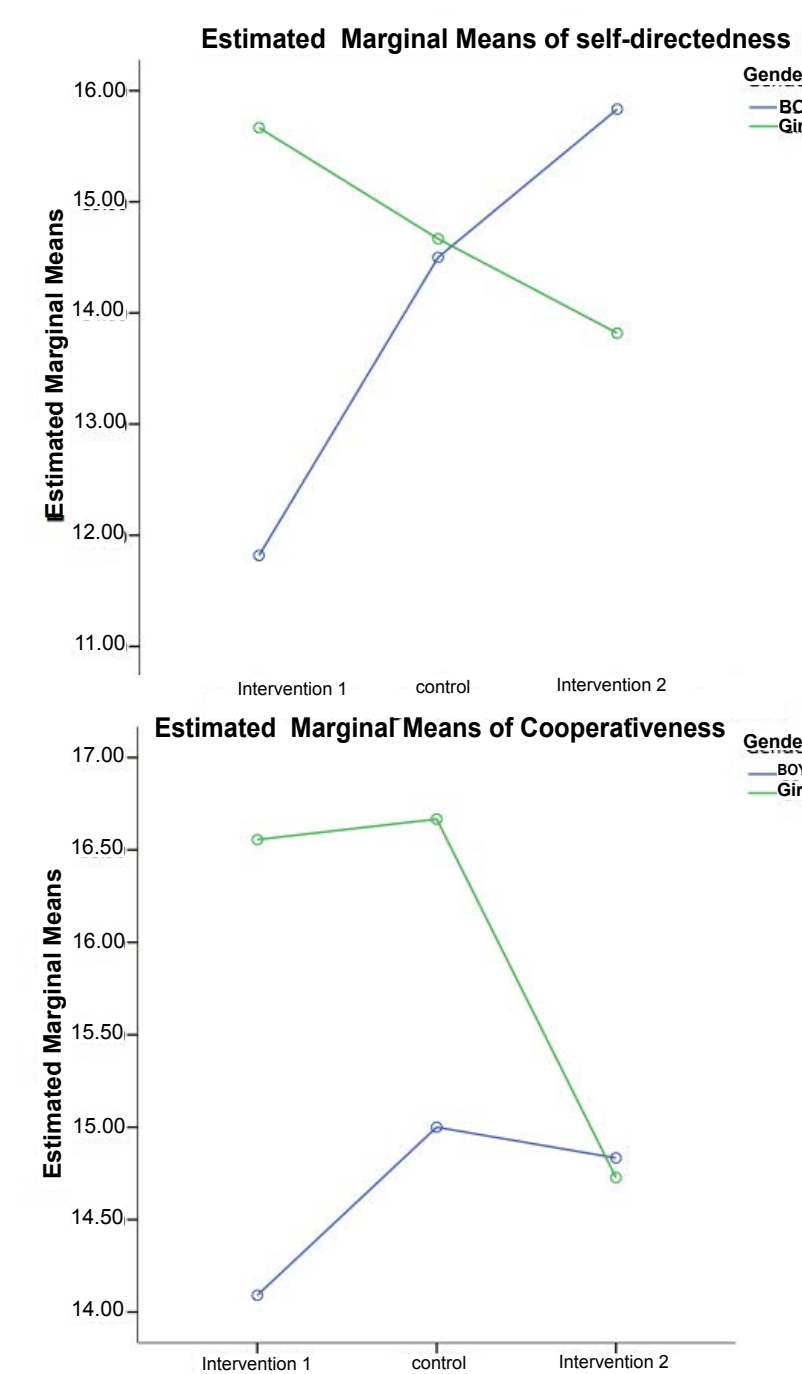

Estimated Marginal Means of self-transcedence

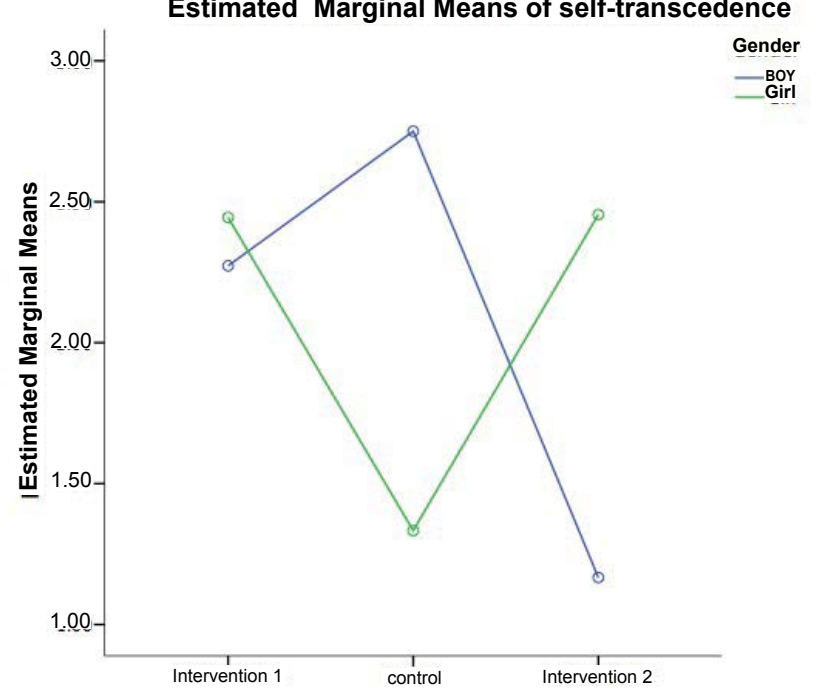

Figure 2: Estimated marginal means in self-directedness (a), cooperativeness (b), and self- transcendence (c) among children in the two interventions and the control group. Note: Intervention 1 = Four Rooms of Change, Intervention $2=\mathrm{EQ}$-workshop.
This specific intervention targets character development and is based on evidence-based techniques centered around a ternary structure of character: self-directedness, cooperativeness, and self-transcendence. Studies investigating its effect on well-being and sustainable personal development are now under development in Swedish settings.

\section{Conflict of Interest}

The development of this article was supported by a grant from AFA Insurance and a grant from The Swedish Research Council (Dnr. 2015-01229). The funders had no role in study design, data collection and analysis, decision to publish, or preparation of the manuscript. Dr. Danilo Garcia is the Director of the Blekinge Center of Competence, which is the Blekinge County Council's research and development unit. The Center works on innovations in public health and practice through interdisciplinary scientific research, person-centered methods, community projects, and the dissemination of knowledge in order to increase the quality of life of the habitants of the county of Blekinge, Sweden. Dr. Kevin M. Cloninger is the Director of the Anthropedia Foundation, a non-profit organization that applies evidenced-based approaches to health and well-being to help and educate people about how to become and stay healthy, positive, inspired, productive, and resilient while facing the stress and challenges of the 21 st century.

\section{References}

1. Holm U (2001) Empati - att förstå andra människors känslor [Empathy - To understand other people's feelings]. Natur Kultur Akademisk.

2. Fahrman M (1996) Barns känslomässiga utveckling. Lund: Studentlitteratur.

3. Manger T, Eikeland OJ, Asbjørnsen A (2001) Effects of social-cognitive training on students' empathy. Swiss Journal of Psychology 60: 82-88.

4. Goldstein TR, Winner E (2012) Enhancing Empathy and Theory of Mind Journal of Cognition and Development 13: 19-37.

5. Selman RL, Byrne DF (1974) A structural-developmental analysis of levels of role taking in middle childhood. Child Development 45: 803-806.

6. Cloninger RC (2004) Feeling Good: The Science of Well-Being. NY: Oxford University Press.

7. Cloninger CR, Przybeck TR, Svrakic DM, Wetzel RD (1994) The temperament and character inventory $(\mathrm{TCl})$ : A guide to its development and use. St. Louis, MO: Center for Psychobiology of Personality, Washington University.

8. Cloninger CR, Svrakic DM, Przybeck TR (1993) A psychobiological model of temperament and character. Arch Gen Psychiatry 50: 975-990.

9. Cloninger CR, Garcia D (2015) The heritability and development of positive affect and emotionality.

10. Josefsson K, Jokela M, Cloninger CR, Hintsanen M, Salo J Hintsa, et al. (2013) Maturity and change in personality: developmental trends of temperament and character in adulthood. Dev Psychopathol 25: 713-727.

11. Garcia D, Lundström S, Brändström $S$, Råstam $M$, Cloninger $C R$, et al (2013) Temperament and Character in the Child and Adolescent Twin Study in Sweden (CATSS): Comparison to the General Population, and Genetic Structure Analysis. PLoS ONE 8: e70475.

12. Lester N, Garcia D, Lundström S, Brändström S, Råstam M, et al. (2016) The Genetic Structure of the Character Sub-Scales of the Temperament and Character Inventory in Adolescence. Annals of General Psychiatry 15: 10

13. Drugge A, Blixt Samuelsson H, Storm U (2014) Sociala och emotionella interventioner I skolans värld. Vad hander med karaktären hos eleverna?.

14. Luby JL, Svrakic DM, McCallum K, Przybeck TR, Cloninger CR (1999) The Junior Temperament and Character Inventory: preliminary validation of a child self- report measure. Psychol Rep 84: 1127-1138.

15. Cloninger CR, Cloninger KM (2011a) Person-centered therapeutics. Int J Pers Cent Med 1: 43-52.

16. Cloninger CR, Cloninger KM (2011b) Development of instruments and evaluative procedures on contributors to illness and health. Int $\mathrm{J}$ Pers Cent Med 1: 456-459.

17. Cloninger CR, Salloum IM, Mezzich JE (2012) The dynamic origins of positive health and wellbeing. Int J Pers Cent Med 2: 179-187.

18. Falhgren E, Nima AA, Archer T, Garcia D (2015) Person-centered osteopathic practice: patients' personality (body, mind, and soul) and health (ill-being and well- being). PeerJ 3: e1349. 